\title{
A case of primary aldosteronism with secondary hyperparathyroidism and bilateral adrenal tumors
}

\author{
Tohru Eguchi and Shozo Miyauchi
}

Department of Internal Medicine, Uwajima City Hospital, 1-1 Gotenmachi, Uwajima, Ehime 798-8510, Japan

Correspondence should be addressed to T Eguchi

Email

26016evian@gmail.com

\section{Summary}

A 43-year-old Japanese woman was admitted to our hospital with weakness. Laboratory findings showed hypokalemia, hypocalcemia and elevation of the serum creatinine phosphokinase levels, but intact parathyroid hormone levels. Further evaluations suggested that she had primary aldosteronism (PA), secondary hyperparathyroidism and bilateral adrenal tumors. She was treated successfully by laparoscopic right adrenalectomy. This case not only serves to the diagnosis of bilateral adrenal tumors in which selective adrenal venous sampling (SAVS) proved to be useful, but also for physicians to be aware of secondary hyperparathyroidism and the risk of secondary osteoporosis caused by PA.

\section{Learning points:}

- The classic presenting signs of PA are hypertension and hypokalemia.

- Hypokalemia can induce rhabdomyolysis.

- PA causes secondary hyperparathyroidism.

- Patients with PA have the risk of osteoporosis with secondary hyperparathyroidism.

- SAVS is useful in bilateral adrenal tumors.

\section{Background}

Primary aldosteronism (PA) represents a cause of secondary arterial hypertension and electrolyte imbalances. PA is typically associated with electrolyte imbalances such as hypokalemia. Hypokalemia can also induce rhabdomyolysis. In recent decades, dynamic studies have demonstrated multiple biological properties of aldosterone on calcium metabolism. We herein report the case of PA with secondary hyperparathyroidism and bilateral adrenal tumors.

\section{Case presentation}

A 43-year-old Japanese woman had a history of hypertension for 5 years and had been on treatment with antihypertensive agents, including amlodipine and candesartan. She noticed recurrent episodes of limb muscle weakness during the previous 2 years. She was admitted to our hospital with severe weakness. Physical examination on admission revealed a blood pressure of $155 / 89 \mathrm{mmHg}$, pulse rate of $81 / \mathrm{min}$, and severe flaccid weakness of the proximal muscles of all four limbs, with relative sparing of the distal groups and tenderness in the lower extremities.

\section{Investigation}

Laboratory findings showed severe hypokalemia $(1.8 \mathrm{mEq} / \mathrm{l})$ and extreme elevation of the serum creatinine phosphokinase (CPK) levels (6929 IU/l). Based on the previous findings, the patient was diagnosed as having 

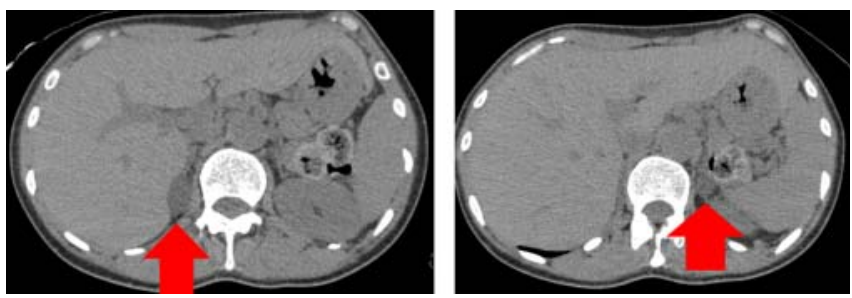

Figure 1

Abdominal computed tomography (CT) showed a low-density right adrenal mass measuring $23 \mathrm{~mm}$ in diameter and a left adrenal mass measuring $15 \mathrm{~mm}$ in diameter.

hypokalemic quadriplegia and rhabdomyolysis. Furthermore, laboratory findings showed lower total serum calcium corrected for albumin (corrected calcium) level $(8.0 \mathrm{mg} / \mathrm{dl})$, elevation of intact parathyroid hormone (PTH) levels $(126.2 \mathrm{pg} / \mathrm{ml})$ and secondary hyperparathyroidism. Because the secondary hyperparathyroidism was related to the high-turnover bone disease, we assessed the bone turnover markers. Tartrate-resistant acid phosphatase 5b (TRACP5b) as bone resorption marker was $247 \mathrm{mU} / \mathrm{dl}$ (normal range 120-420 mU/dl), whereas procollagen type I N-terminal propeptide (PINP) as bone formation marker was $32.4 \mu \mathrm{g} / \mathrm{l}$ (normal range 17.1-64.7 $\mu \mathrm{g} / \mathrm{l})$. The lumbar bone mineral density (BMD) was $110 \%$ of the young adult mean (YAM) and the femoral neck BMD was $85 \%$ of YAM. Osteopenia or osteoporosis was not present.

Treatment was initiated by oral and intravenous supplementation of potassium, which was followed within two weeks by resolution of the symptoms and return of the serum CPK levels to normal, without the development of any renal complication. Two weeks after stopping amlodipine and candesartan, further evaluation revealed extremely high aldosterone-renin ratio (ARR) (more than $3083 \mathrm{pg} / \mathrm{ml}$ per $\mathrm{ng} / \mathrm{ml}$ per $\mathrm{h}$ ) and elevated urinary aldosterone excretion $(70.1 \mu \mathrm{g} /$ day). Abdominal computed tomography (CT) showed a low-density right adrenal mass measuring $23 \mathrm{~mm}$ in diameter and left adrenal mass measuring $15 \mathrm{~mm}$ in diameter (Fig. 1). Serum cortisol showed the typical circadian rhythm. Serum cortisol was sufficiently suppressed with a $1 \mathrm{mg}$ overnight dexamethasone suppression test. The level of ARR was still high after the captopril test (more than $200 \mathrm{pg} / \mathrm{ml}$ per $\mathrm{ng} / \mathrm{ml}$ per h). Plasma renin activity (PRA) remained suppressed $(0.2 \mathrm{ng} / \mathrm{ml}$ per $\mathrm{h})$ after stimulation with furosemide $(40 \mathrm{mg}$ ) plus upright posture for $60 \mathrm{~min}$ when hypotensive episodes occurred. ${ }^{131}$ I-adosterol scintigraphy showed increased uptake of the tracer in the right adrenal gland (Fig. 2).
Subsequently, the plasma aldosterone concentration (PAC) and plasma cortisol levels in adrenal venous effluents obtained by selective adrenal venous sampling (SAVS) before and after ACTH (Cortrosyn: $250 \mu \mathrm{g}$ ) stimulation are shown Table 1. Basal aldosterone levels in the right and left adrenal vein were $28000.0 \mathrm{pg} / \mathrm{ml}$ and $484.7 \mathrm{pg} / \mathrm{ml}$, respectively, which rose to $31000.0 \mathrm{pg} / \mathrm{ml}$ and $3081.8 \mathrm{pg} / \mathrm{ml}$, respectively, $20 \mathrm{~min}$ after ACTH stimulation. The aldosterone concentrations in the right adrenal vein were greater than $2500 \mathrm{pg} / \mathrm{ml}$ before ACTH stimulation and greater than $14000.0 \mathrm{pg} / \mathrm{ml} 20 \mathrm{~min}$ after ACTH stimulation, which suggested unilateral hypersecretion of aldosterone from the right adrenal gland. Based on the cortisol levels in the right and the left adrenal veins after ACTH stimulation (970.0 and $344.0 \mu \mathrm{g} / \mathrm{dl}$; more than $200 \mu \mathrm{g} / \mathrm{dl}$ ), we considered that the catheters had been correctly inserted into the adrenal vein. We also took into account the ratio of aldosterone/cortisol (A/C) on the right side to that on the left side after ACTH stimulation (the A/C ratio), which was 3.6 $(>2.6)$. The data obtained from SAVS strongly suggested preferential aldosterone hypersecretion from the right adrenal gland. All these results strongly suggest the presence of prominent excess of aldosterone from the right adrenal gland in this case.

\section{Treatment}

The patient was treated successfully by laparoscopic right adrenalectomy. The histology of the resected specimen was consistent with functioning adrenal adenoma. Immunohistochemical analysis of $3 \beta$-hydroxysteroid dehydrogenase ( $3 \beta$-HSD) showed positive immunoreactivity in cortical cells of the nodules (Fig. 3a) and hyperplastic zona glomerulosa cells (Fig. 3b).

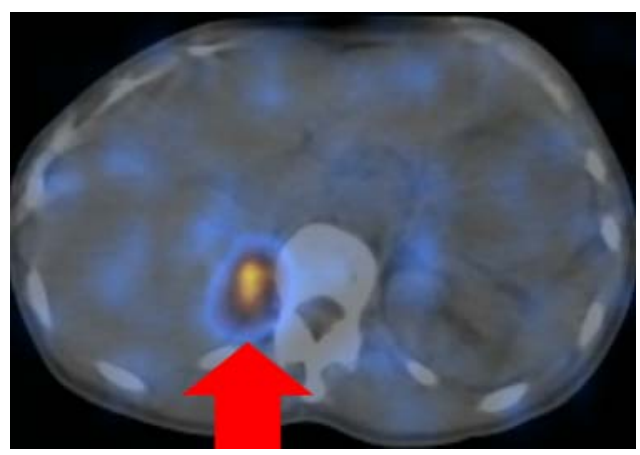

Figure 2

${ }^{131}$ I-adosterol scintigraphy showed increased uptake of the tracer in the right adrenal gland. 
Table 1 Selective adrenal venous sampling.

\begin{tabular}{|c|c|c|c|}
\hline & $\begin{array}{c}\text { Inferior } \\
\text { vena cava }\end{array}$ & $\begin{array}{c}\text { Right } \\
\text { adrenal } \\
\text { vein }\end{array}$ & $\begin{array}{c}\text { Left } \\
\text { adrenal } \\
\text { vein }\end{array}$ \\
\hline \multicolumn{4}{|c|}{ Before ACTH stimulation } \\
\hline PAC (pg/ml) & 556.9 & 28000.0 & 484.7 \\
\hline Cortisol ( $\mu \mathrm{g} / \mathrm{dl})$ & 13.3 & 36.4 & 28.7 \\
\hline $\mathrm{A} / \mathrm{C}$ & 41.9 & 769.2 & 16.9 \\
\hline \multicolumn{4}{|c|}{ After ACTH stimulation } \\
\hline PAC (pg/ml) & 1080.0 & 31000.0 & 3081.8 \\
\hline Cortisol ( $\mu \mathrm{g} / \mathrm{dl})$ & 20.1 & 970.0 & 344.0 \\
\hline $\mathrm{A} / \mathrm{C}$ & 53.7 & 32.0 & 9.0 \\
\hline
\end{tabular}

\section{Outcome and follow-up}

After the operation, the patient's symptoms improved, the PAC and PRA reverted to normal and the serum potassium levels also returned to and remained normal. PTH and fractional excretion of calcium (FECa) decreased, whereas corrected calcium elevated. Furthermore, TRACP5b as a bone resorption marker decreased, whereas PINP as bone formation marker increased (Table 2). There was no recurrence 1 year after the operation. However, the contra-lateral adrenal mass should be followed up morphologically and functionally.

\section{Discussion}

We present here a case of PA with secondary hyperparathyroidism and bilateral adrenal tumors. The mechanism of secondary hyperparathyroidism with PA is as follows. Hyperaldosterone leads to hypercalciuria and hypocalcemia which cause secondary hyperparathyroidism. The hypercalciuria associated with aldosteronism is thought to be related to an expansion of extravascular fluid volume with resultant reductions in proximal tubular $\mathrm{Na}^{+}$and $\mathrm{Ca}^{2+}$ resorption. This leads to their increased delivery to distal segments of the nephron, where the mineralocorticoid promotes $\mathrm{Na}^{+}$resorption without affecting $\mathrm{Ca}^{2+}$ which results in hypercalciuria (1). Furthermore, accumulating clinical evidence suggests a bidirectional interplay between PTH and aldosterone (2). In particular, hyperaldosteronism is reported to elevate urinary calcium excretion (3). Pilz et al. (4) reported in ten PA patients lower serum calcium and higher plasma PTH levels compared to essential hypertension (EH) patients. Maniero et al. (5) showed a highly significant $31 \%$ increase in the number of cases of hyperparathyroidism. Ceccoli et al. (6) in 116 PA patients compared with $110 \mathrm{EH}$ patients showed urinary calcium excretion and an elevation of PTH levels.
In bone metabolism, Pilz et al. documented significantly lower BMD in PA patients compared to patients without hyperaldosteronism. The mechanism underlying this association is directly by aldosterone-mineralocorticoid receptors (MR)-mediated effects on osteoblasts and osteoclasts and indirectly by PTH levels and increased bone reabsorption (7). Maniero et al. (8) demonstrated the expression of the MR in both PTH secreting adenoma and in parathyroid tissue, and MR was predominantly located in the nucleus of the parathyroid cells. Finally, Tomaschitz et al. (2) showed that patients with PA were with secondary hyperparathyroidism that could be successfully treated with either mineral corticoid receptor antagonists or adrenal surgery.

Our patient showed hypersecretion of aldosterone from the right adrenal gland because of the greater PAC in the right adrenal vein after ACTH stimulation and ${ }^{131} \mathrm{I}$-adosterol scintigraphy showed increased uptake of the tracer in the right adrenal gland. The histology of the resected specimen was functioning adrenal adenoma. Immunohistochemical analysis of $3 \beta$-HSD showed positive immunoreactivity in cortical cells of the nodules and hyperplastic zona glomerulosa cells. These data show not only the cortical cells of micronodules actively synthesize aldosterone, but also what the hyperplastic zona glomerulosa cells might do. Nishimoto et al. (9) demonstrated that immunohistochemistry of the human normal adrenal cortex for Aldosterone synthase (CYP11B2) may provide a pathological confirmatory diagnosis of adrenocortical adenomas, but we cannot investigate the immunohistochemistry of CYP11B2. In bone metabolism, lower corrected calcium level, elevation of PTH level and secondary hyperparathyroidism could be successfully treated with adrenal surgery.

Our patient was also diagnosed as rhabdomyolysis. Rhabdomyolysis is a disorder characterized by acute damage of the skeletal muscle and caused by various conditions such as muscle diseases, intense exercise,
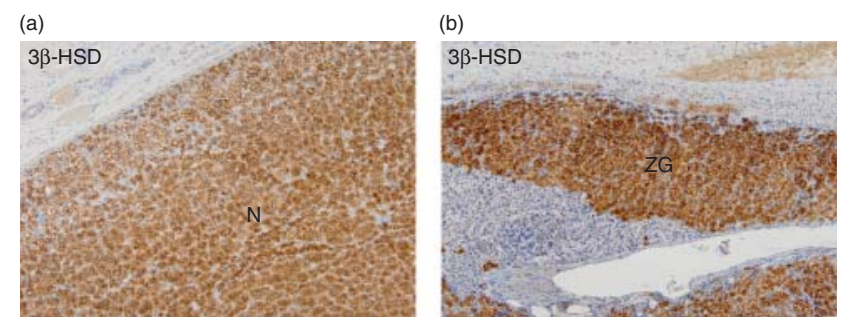

Figure 3

(a) The cortical cells of the nodules $(N)$ showed positive immunostaining for $3 \beta$-HSD ( $\times 10)$. (b) Hyperplastic zona glomerulosa (ZG) cells also showed positive immunostaining for $3 \beta-H S D(\times 10)$. 
Table 2 Postoperative course.

\begin{tabular}{|c|c|c|}
\hline & Preoperative & Postoperative \\
\hline PRA (ng/ml per h) & 0.2 & 2.1 \\
\hline PAC (pg/ml) & 616.5 & 140.5 \\
\hline PAC/PRA & 3082.5 & 66.9 \\
\hline Intact-PTH (pg/ml) & 126.2 & 37.3 \\
\hline Corrected Ca (mg/dl) & 8.0 & 8.8 \\
\hline$P(m g / d l)$ & 2.6 & 3.3 \\
\hline FECa (\%) & 1.1 & 0.5 \\
\hline TRACP5b (mU/dl) & 247 & 164 \\
\hline PINP $(\mu g / l)$ & 32.4 & 45.4 \\
\hline BMD lumber (\%YAM) & 110 & 106 \\
\hline Femoral (\%YAM) & 85 & 82 \\
\hline
\end{tabular}

dehydration, various drugs such as statins, infections, poisoning and hypokalemia. Hypokalemia may potentially cause rhabdomyolysis by three mechanisms. First, increased blood flow to the anaerobic muscle is mediated by release of intracellular potassium into the extravascular spaces. With hypokalemia, release of potassium may be inadequate to vasodilate arterioles and capillaries that perfuse the exercising muscle. Second, hypokalemia has been shown to suppress the synthesis and storage of glycogen, an intracellular store of energy substrate for the exercising muscle. Finally, deranged ion transport across the cell membrane has been demonstrated (10).

In conclusion, this case provides an important lesson that further investigation of the cause of hypokalemia must be pursued. The present case also serves to the diagnosis of bilateral adrenal tumors in which SAVS proved to be a useful diagnostic tool for its localization. However, a long-term follow-up is needed to observe whether or not aldosterone hypersecretion may occur from the left adrenal gland tumor. Furthermore, the present case serves to underscore the need for physicians to be aware of secondary hyperparathyroidism and the risk of secondary osteoporosis caused by PA.

\section{Declaration of interest}

The authors declare that there is no conflict of interest that could be perceived as prejudicing the impartiality of the research reported.

\section{Funding}

This research did not receive any specific grant from any funding agency in the public, commercial or not-for-profit sector.

\section{Patient consent}

The authors confirm that written informed consent was obtained from the patient for publication of the submitted article and accompanying images through his signature on their consent form.

\section{Author contribution statement}

Dr S Miyauchi attended to the patient and contributed to the writing of this case report.

\section{References}

1 Schneider EG, Goldsmith RS, Arnaud CD \& Knox FG 1975 Role of parathyroid hormone in the phosphaturia of extracellular fluid volume expansion. Kidney International 7 317-324. (doi:10.1038/ ki.1975.44)

2 Tomaschitz A, Ritz E, Pieske B, Rus-Machan J, Kienreich K, Verheyen N, Gaksch M, Grubler M, Fahrleitner-Pammer A, Mrak P et al. 2014 Aldosterone and parathyroid hormone interactions as mediators of metabolic and cardiovascular disease. Metabolism: Clinical and Experimental 63 20-31. (doi:10.1016/j.metabol.2013.08.016)

3 Resnick LM \& Laragh JH 1985 Calcium metabolism and parathyroid function in primary aldosteronism. American Journal of Medicine $\mathbf{7 8}$ 385-390. (doi:10.1016/0002-9343(85)90328-6)

4 PilzS, Kienreich K, Drechsler C, Ritz E, Fahrleitner-Pammer A, Gaksch M, Meinitzer A, März W, Pieber TR \& Tomaschitz A 2011 Hyperparathyroidism in patients with primary aldosteronism: cross-sectional and interventional data from the GECOH study. Journal of Clinical Endocrinology and Metabolism 97 E75-E79. (doi:10.1210/jc.2011-2183)

5 Maniero C, Fassina A, Seccia TM, Toniato A, Iacobone M, Plebani M, De Caro R, Calo LA, Pessina AC \& Rossi GP 2012 Mild hyperparathyroidism: a novel surgically correctable feature of primary aldosteronism. Journal of Hypertension 30 390-395. (doi:10.1097/HJH. Ob013e32834f0451)

6 Ceccoli L, Ronconi V, Giovannini L, Marcheggiani M, Turchi F, Boscaro M \& Giacchetti G 2013 Bone health and aldosterone excess. Osteoporosis International 24 2801-2807. (doi:10.1007/s00198-013-2399-1)

7 Rossi E, Sani C, Perazzoli F, Casoli MC, Negro A \& Dotti C 1995 Alterations of calcium metabolism and of parathyroid function in primary aldosteronism, and their reversal by spironolactone or by surgical removal of aldosterone-producing adenomas. American Journal of Hypertension 8 884-893. (doi:10.1016/0895-7061(95)00182-O)

8 Maniero C, Fassina A, Guzzardo V, Lenzini L, Amadori G, Pelizzo MR, Gomez-Sanchez C \& Rossi GP 2011 Primary hyperparathyroidism with concurrent primary aldosteronism. Hypertension 58 341-346. (doi:10.1161/HYPERTENSIONAHA.111.173948)

9 Nishimoto K, Nakagawa K, Li D, Kosaka T, Oya M, Mikami S, Shibata H, Itoh H, Mitani F, Yamazaki T et al. 2010 Adrenocortical zonation in humans under normal and pathological conditions. Journal of Clinical Endocrinology and Metabolism 95 2296-2305. (doi:10.1210/ jc.2009-2010)

10 Allison RC \& Bedsole DL 2003 The other medical causes of rhabdomyolysis. American Journal of the Medical Sciences 326 79-88. (doi:10.1097/00000441-200308000-00005)

Received in final form 28 May 2015 Accepted 19 June 2015 